\title{
APPLICATION OF ORANiZATIONAL TOOLS AND SOFTWARE SOLUTIONS IN ORDER TO INCREASE THE EFFICIENCY OF BUSINESS PROCESSES
}

\author{
STOJKIČ, Ž.; VIŠEKRUNA, V. \& MAJSTOROVIČ, V.
}

Abstract: In this chapter the intention is to stress the importance of connection between organisational Lean tools and software tools that have great flexibility and ability to adapt to business processes of companies. LEAN management means creating more value for the customer by using fewer resources. Lean organisation knows which values their customers require and focuses its key processes to continuously add value to the customer. Loss elimination in the whole process instead of in certain parts of the system only creates processes that need less human effort, less space, less capital and less time to develop a product or to perform a service. On the other hand, CRM as a concept and software tool have significantly contributed to improving relationship with customers. Development of CRM system is oriented by xRM (Anything relationship management). Processes which can be covered by these solutions are no longer related to customer relations only, but to a large number of other processes such as managing relationships with suppliers, managing employee relations and managing machinery maintenance. This paper wants to show that combining concepts of $x R M$ and Lean can lead to the increase of efficiency and transparency of business processes. $x R M$ strategies and tools have the ability to automate processes thereby achieving greater efficiency and transparency of the process and simpler controlling which is enabled by technology development. Of course, xRM solutions will not replace business processes covered by ERP solutions but allow us to cover business processes that are not covered by ERP software solutions. On the other hand, Lean management tools provide methods and techniques for the analysis of processes and their improvement. Combination of these organisational and software tools can directly affect significant increase of the efficiency and transparency of business processes. Future development of xRM solutions and its components will allow easier imaging of business processes without the need for direct programming of application by a programmer. By applying Lean methods and tools it will be possible to image and continuously improve these processes, which will increase the degree of efficiency of the processes themselves but also the degree of utilisation of xRM solutions.

Key words: CRM, Lean management, software, improvement
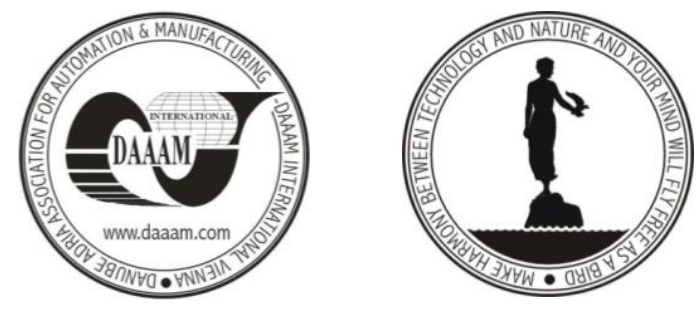

Authors' data: Doc. Dr. Stojkič, Ž[eljko]; Prof. Dr. Višekruna, V[ojo]; Prof. Dr. Majstorovič, V[lado], Faculty of engineering and computer science, Matice hrvatske, bb, 88000, Mostar, Bosna I Herzegovina, zeljko.stojkic@sve-mo.ba,vojo.visekruna@sve-mo.ba,

vlado.majstorovic@sve-mo.ba

This Publication has to be referred as: Stojkic, Z[eljko], Visekruna, V[ojo] \& Majstorovic, V[lado] (2013) Application of Organizational Tools and Software Solutions in Order to Increase the Efficiency of Business Processes, Chapter 07 in DAAAM International Scientific Book 2013, pp. 173-192, B. Katalinic \& Z. Tekic (Eds.), Published by DAAAM International, ISBN 978-3-90150994-0, ISSN 1726-9687, Vienna, Austria

DOI: $10.2507 /$ daaam.scibook.2013.07 


\section{Introduction}

CRM, or Customer Relationship Management, is an old business concept that is becoming topical again thanks to the technology that enables and supports it. The basic idea of CRM is not only product-orientated companies, but also creating personalised lasting relationship with their customers. It is desirable that the products and services are adapted to the requirements and specifications of individual customers, and it has become possible with the development of databases that enable you to store data on individual users and with the development of software that enables the analysis and optimal use of these data.

CRM is a relatively simple concept that refers to the understanding of customer requirements and actions, in order for the company to be able to meet those needs and build strong relationships with customers, so that all this could lead to increased customer loyalty and increased sales.

\begin{tabular}{|l|l|}
\hline OLD APPROACH & NEW APPROACH \\
\hline Attract new customers & Retain existing customers \\
\hline Get orders & Become preferred supplier \\
\hline Identical customer management & Managing every customer in a specific way \\
\hline Sell to anyone & Focusing on customers who generate profit \\
\hline
\end{tabular}

Tab. 1. Approaches in customer relations

Customer is a party that is involved in the process of acquiring assets (enrichment) of a company in the form of purchase of goods and services and that is of interest for the company. According to research, costs of attracting a new customer are 7 to 10 times higher than the costs of retaining an existing one.

One goal of CRM is to transform valuable data regarding clients into knowledge about them. This knowledge must be recorded, stored, accessible and open for analysis, so that management and employees could have access and use it for better understanding of past and present environment and predicting its future operating results.

CRM includes:

Preliminary identification of needs and desires of customers; Differentiation of customers - according to needs and importance in order to achieve goals of the organisation; Interaction with customers - identification of customer needs; The design of products/services offered to groups of customers.

\section{CRM as a Pilosophy and as a Software Tool}

The concept of customer relationship management evolved through history. In the beginning, the only way to contact the client was in person. The invention of phone allowed the improvement of relations with clients. Over time, the phone has 
become an important means by which company clients were trying to obtain necessary information. These changes lead to the formation of an organisational unit within companies termed call centre. Contact centres evolved from call centres, where the main difference between the call and contact centre derives from the name. Both centres serve for establishing communication between office staff and the client, where in the era of call centres classical fixed phones were the main medium of communication, while contact centres provide much more diverse channels and forms of communication, and the emphasis is on the use of various Internet services such as e-mail, www, Internet telephony, mobile devices to access the Internet, etc. (http://arhiva.trend.hr/clanak.aspx?BrojID=71\&KatID=22\&ClanakID=783)

Software tools to support CRM strategy in its current form have been developed in several phases. There were applications that were developed before discovering the CRM philosophy and served for accelerating the process of selling or marketing. This refers primarily to the precursors SFA (Sales Force Automation) and Field Service Automation. They were later called Customer-Facing Applications. Help Desk Applications were known as Contact Management Applications. With the advent of a new trend, CRM, they were adapted to the new philosophy. The basic structure of the system to support the CRM strategy consists of three parts:

- Operational - basic business processes (marketing, sales, services)

- Analytical -support in the analysis of consumer behaviour and implements business philosophy as well as technology

- Collaborative -contacting consumers by phone, fax, Internet, mail, in person, etc.

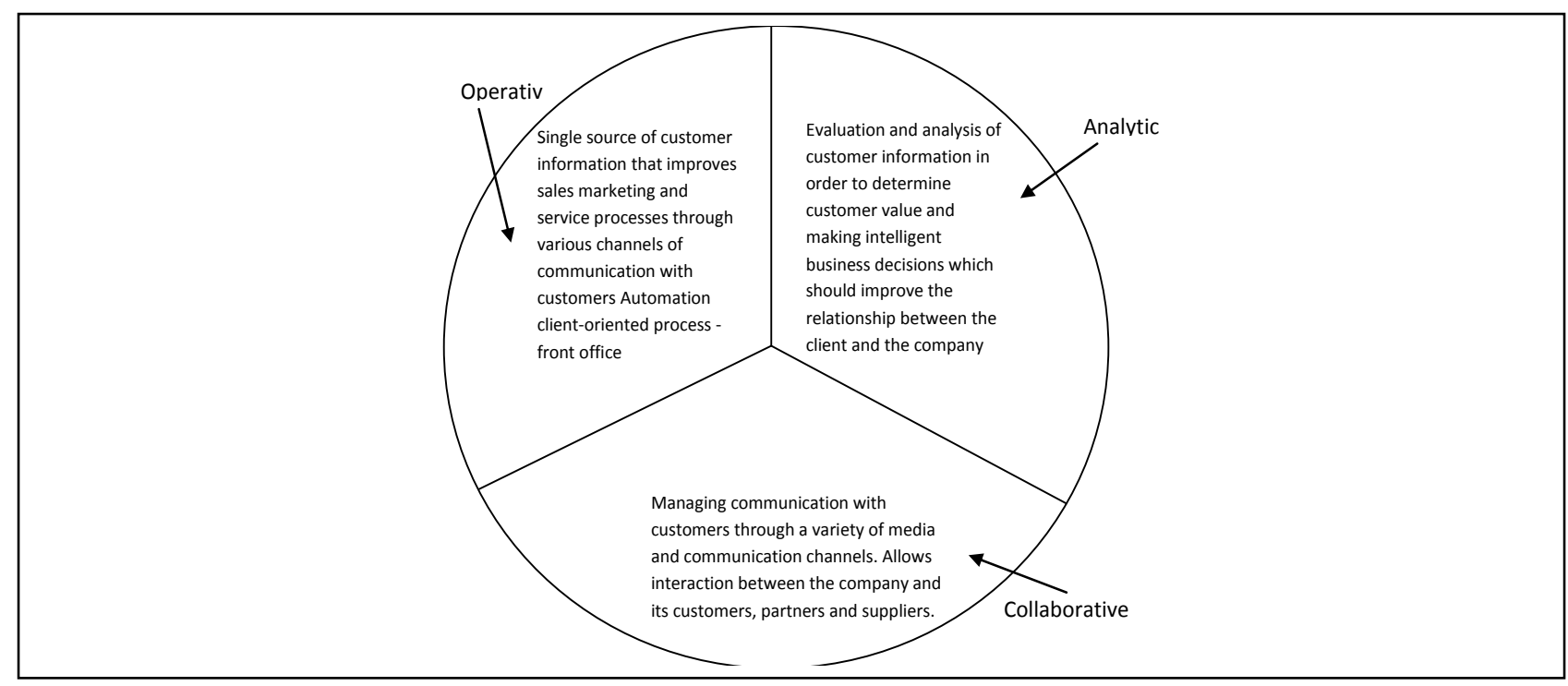

Fig. 1. Components of CRM (Kramer, 2002)

\subsection{Operational CRM}

Operational CRM provides automation of the process of marketing, sales and services. It also allows for exchange of customer data between different departments of the company. It is responsible for daily communication with the client. It collects, stores, extracts, processes, interprets and reports on customer data. (Kramer, 2002) 
Operational CRM provides support for business activities of the "front office", i.e. activities that are in direct contact with clients. This includes sales, marketing and service offices. Operational CRM combines three types of operations:

\section{SFA - sales force automation}

SFA includes the most important functions of sales and sales management. This encompasses account management, contact management, forecasting, sales management, monitoring client desires, and customer purchasing habits. SFA tools are designed to increase the productivity of sales.

\section{CSS - customer service and support}

CSS is responsible for the automation of service requests, complaints, product returns and processing information requests.

\section{EMA - enterprise marketing automation}

EMA provides information about the business environment, competitors, industry trends, macroclimate and conducting marketing campaigns in order to increase effectiveness of marketing campaigns. The main functions are demographic analysis, segmentation, and forecasting.

\subsection{Analytical CRM}

Analytical CRM is not in direct contact with clients. Analytical CRM handles a full range of data collected from operational and collaborative CRM, and, based on the results, it brings, i.e. generates, decisions and strategies. It is based on data warehousing, i.e. data storage system. Data processing results in adopting clients' behaviour pattern based on which the offer is personalised. Many analytical methods are used while processing these data and they create a clean and comprehensive picture of the client and his needs. This helps greatly when planning marketing activities. (Kramer, 2002)

Key indicators provided by analytical CRM applications as a basis for making strategic business decisions, include:

- Market share

- Number of consumers

- List of the most profitable consumers

- Consumer satisfaction index

- Loyalty index (a key indicator of the deepening of relationships between companies and consumers)

- Customer retention rate (the ratio of the number of consumers who are reusing company products and services and the total number of consumers)

- Response rate (the rate of response of the target consumer group to a specific marketing measure)

- Data related to the particularities of individual consumers, e.g. the total value brought by a consumer, which is then used for direct marketing towards that consumer.

Key indicators and methods of the analytical CRM form a solid basis for forecasting, planning, measurement and optimisation of all business processes that put consumers at the centre of attention. 


\subsection{Collaborative CRM}

Collaborative CRM enables interaction between companies and clients, partners and suppliers. In his communication, where the client sees only collaborative CRM, it is the interface to the client. It represents contacts, e-mail, web, applications, etc. Collaborative CRM includes everything related to the contact with the client and connects many parts and processes that facilitate contact for the company, i.e. collaboration with the client.

Collaborative CRM provides and includes a number of channels of contacts with the client. Contact with the client, i.e. client information, is collected through a call centre, e-mail, web, conferences and direct interaction with the client. The main goal of the collaborative CRM is to improve the quality of communication with the client, which effectively implies a higher level system for collecting information about the client. (Kramer, 2002)

\section{Architecture of CRM-oriented Systems}

Architecture refers to the method of building applications to support the realisation of CRM strategy, method of arrangement in hardware and software environment and method for using these software tools. The choice of applications is mostly influenced by its functionality, but architecture should also have a significant role because it determines capabilities and ease of integration into existing environment, testifies about the technology used in building, adaptation and integration.

The most important criteria for the assessment of CRM architecture are (Martens, 2009):

\subsection{Environment}

Environment includes those software products that the application supports (operating systems, web servers, server platforms, databases). The environment is the simplest criterion for the selection of one of software tools to support the realisation of CRM strategy, because it can facilitate the choice between more of them. The selected product must be able to function in the existing environment, and the most important environments are server platforms and databases. Majority of CRM systems support the most commonly used server platforms (Microsoft NT/2000 and Sun Solaris) and databases (IBM DB2, Microsoft SQL Server and Oracle Server). (Martens, 2009)

\subsection{Organisation}

Organisation identifies the main components of the application to support CRM strategy, interfaces between them and protocols used for communication. It contains a description of the application layers and information on whether the application is web-oriented (which is usually the case).

Modern CRM systems are three-layer designs with the following layers:

1. Client

2. Application server

3. Database 
We can get better insight into the product availability, scalability and management techniques by studying the number and types of components, and the ways in which they can communicate with each other. (Martens, 2009)

\subsection{Infrastructure}

Infrastructure within the architecture of software tools to support CRM strategy indicates services at system level, which are independent of the application itself, and they perform basic service activities related to their functioning, including: memory and process management (processors), management of transactions, queues, processing strings, application processing, routing and arrangement, etc.

Portals are another addition to the infrastructure of CRM-oriented systems. They allow users to access a range of applications and data. The advantage is that, within a single session, users access multiple applications, watch a variety of reports and study business performances with multiple views. Portals allow the integration of applications and data at user interface level. (Martens, 2009)

\subsection{Structure}

Structure declares the way (organisation) of building applications to support the CRM strategy (client/server) and the content of these components (what is the client and what is the server). If the application is web-oriented, as far as its organisation is concerned, it is logical that its structure, typically three-layer, will be web-oriented and its parts will have the following building elements:

- Websites

- Program logic

- Data model

Understanding product structure provides insight into the skills, effort and additional resources that will be required for product implementation, customisation, support and maintenance, as well as integration with external applications. Structure which is based on standard and popular technologies facilitates the entire work. (Martens, 2009)

\subsection{Customisation}

Customisation refers to the activities while software tool to support the CRM strategy correspondents to the specificity of the company in the field of business and information structure. This means that no tool can be applied in a certain company without adjustment to the specific business terms and conditions of that specific economic subject. This primarily refers to operational applications. Analytical applications are normally not adjusted in terms of program logic or user interface. Customisation should be distinguished from configuration. Configuration means changing the way the application works by adjusting values of parameters, without changing the internal logic. Customisation means modifying the influence of external parameters on the functioning of the CRM-oriented systems (change of the internal 
logic of the system). Any adjustment is in fact a kind of re-engineering. (Martens, 2009)

\subsection{Integration}

Integration refers to the ability of connecting software tools to support the realisation of the CRM strategy with other (internal and external) systems of the company. This is a necessary action before the introduction of any software product. CRM-oriented systems provide the company with a wide range of functionality related to users. The product has to be adjusted to reflect the way the company operates. The most important feature of this software tool is to enable overall view of clients by collecting data about them from many diverse sources and to ensure unique access to data across all applications. Integration is the most demanding job in the implementation of software tools to support the CRM strategy. (Martens, 2009)

\section{4. xRM - New Paradigm of Traditional CRM}

One new phenomenon is the introduction of CRM without explicit emphasis on the client or customer, and so the CRM acronym is now being replaced with the new $\mathrm{xRM}$ acronym where xRM represents the management of any type of relationship. $\mathrm{xRM}$ began to appear in legal departments, purchasing departments, finance, human resources, project offices and various back office processes. Moving CRM towards $\mathrm{xRM}$ leads to a large-scale demystification of CRM process so that it stops being an island that aggregates data from other systems and it becomes an integral part of everyday processes.

xRM capabilities :

- CRM-oriented systems support sales, marketing and customer service department; xRM-oriented systems can support any department in the organisation

- CRM-oriented systems automate processes in marketing, sales and customer service; $\mathrm{xRM}$-oriented systems automate any business process or connection of greater significance

- CRM-oriented systems provide insight into the interactions, activities and tasks; xRM-oriented systems do exactly the same for "anything" or "anyone".

xRM-oriented systems enable functionalities such as: data management, creating a flowchart, recording user experience, access and security, making analysis and reports. As far as adjustment is concerned, configuration of the basic application was done through a visual user interface, so that non-technical resources can quickly create and configure applications. (http://www.articlesbase.com/softwarearticles/modules-of-crm-solutions-1158092.html)

$$
\begin{array}{|l|l|}
\text { C }- \text { client } & \mathbf{x}-\text { any } \\
\hline
\end{array}
$$


Stojkic, Z., Visekruna, V. \& Majstorovic, V.: Application of Organizational Tools...

\begin{tabular}{|l|l|l|}
\hline & CRM & xRM \\
\hline Usage & $\begin{array}{l}\text { Marketing, sales and customer } \\
\text { service }\end{array}$ & Any team \\
\hline Management & Relationship with clients & Any relationship \\
\hline Automation & $\begin{array}{l}\text { Marketing, sales and processes of } \\
\text { business services }\end{array}$ & Any significant process \\
\hline Overview & $\begin{array}{l}\text { Interactions, activities, tasks and } \\
\text { annual history }\end{array}$ & $\begin{array}{l}\text { Interactions, activities, tasks and } \\
\text { annual history for X }\end{array}$ \\
\hline Provides & Client-oriented analysis & X-oriented analysis \\
\hline Integration with & ERP applications & ERP and CRM applications \\
\hline
\end{tabular}

Tab. 2. Comparison of CRM and XRM (http://www.articlesbase.com/softwarearticles/modules-of-crm-solutions-1158092.html)

\section{Lean Management as a Philosophy and Tools}

According to the APICS Dictionary, the essence of lean production is to emphasize minimisation of the amount of used resources (including time in various activities in the company). This includes identification and elimination of activities that do not add value in development, production, supply management chain and communication with customers. Lean manufacturers have teams of employees with multiple skills at all levels of the company and they use highly flexible and increasingly automated machines in order to produce large volumes of products with potentially big variations. "Lean" philosophy sets out principles and practice of reducing costs through elimination of waste and simplification of all manufacturing and support systems. Conditions that led to the development of this system of production appeared after the Second World War, when Japanese carmakers faced serious competition from the U.S. manufacturers.

Toyota Motor Corporation realised that the only way to survive was to offer the Japanese (and world's) consumers the only thing that American manufactures could not offer at that time - variations of the product - while at the same time maintaining quality, short delivery time and lowest possible prices .

Facing tough competition in terms of quality and price, market opportunity for the increases number of variations of the product, limited productive resources and raw materials, Toyota had to create a new radical way of production in order to survive. The result was the aforementioned TPS, which methodically eliminated any waste in the production process and remained focused on meeting customer demand. This approach revolutionized car production with the kaizen, poka-yoke, and kanban methods, with updates and deliveries to the place of use, and innovations on the assembly lines, which are now the basis of almost every car factory around the world. Today's concept of lean production originated from the TPS, and the word "lean" comes from the main principle of using less of everything (for example fewer employees, less space, less inventory, less movement, etc.) than in traditional production processes, although there are more product variations . 
In other words, the basis of philosophy is focused on creating activities that bring value to the customer, system identification, elimination of waste and continuous improvement of the production environment in order to increase productivity.

Primary focus is on the activities that create value to the customer, while elimination of waste and constant improvement are a result of these activities.

\subsection{Basic Principles of Lean}

The concept of Lean refers to a system of methods that emphasize identification and elimination of all activities that do not add value or remove waste from producer's organisations or organisations that are involved in the production process. Consequence of Lean is that processes are becoming faster and cheaper. The lean model tries to reduce the number of processes in order to keep only the most important ones for the company's business. The ultimate goal is to reduce the time between the order from the customer and delivery of goods (lean time), so as to eliminate all unnecessary actions. The result is a reduction in organisational costs, turnaround time, and the number of unnecessary operations, which increases competitiveness and flexibility in terms of market demands. Lean should be involved in the development, procurement, production and distribution of products and seen as a direction to follow rather than a state to be achieved.

Development of principles, concepts and tools of Lean production is attributed to Toyota's engineer Taiichi Ohno, although he said that he had taken most of the ideas from the work of Henry Ford - FMC.

The term Lean was later developed and popularized by a team of experts from the Massachusetts Institute of Technology (MIT) within the International Motor Vehicle Programme (IMVP), in order to describe new production techniques introduced by Ohno.

Companies that apply this system differ from the traditional ones as shown in Table 3 (http://www.productivityinc.com/pdf/MoMRwebcast5.pdf, Mapping your way to Lean Maintenance, John Kravontka).

\begin{tabular}{|l|l|}
\hline \multicolumn{1}{|c|}{ TRADITIONAL ORGANISATION } & \multicolumn{1}{c|}{ LEAN ORGANISATION } \\
\hline Complex Simple & Complex Simple \\
\hline Budget-driven Demand-driven & Demand-driven \\
\hline Excessive stock & Needs-driven stock \\
\hline Accelerating activities that add value & Reducing activities that do not add value \\
\hline Mass production & Production in small series \\
\hline Long time from order to delivery & Minimal time from order to delivery \\
\hline Inspection-based quality & Quality built into the design \\
\hline Operating departments & Process orientation \\
\hline
\end{tabular}

Tab. 3. Differences between traditional and Lean organisation

(http://www.productivityinc.com/pdf/MoMRwebcast5.pdf, Mapping your way to Lean Maintenance, John Kravontka)

Lean management emphasizes production of small series and progress of individual pieces. Lean production is based on knowledge management and change 
management. Lean company implies "Lean employees" where employees have to "become Lean" before the company becomes Lean. Lean company should provide employees with experience, knowledge and skills. Experience is acquired over time, but there has to be support. Knowledge and skills come with education and training, so management has to understand the needs and continually educate and train employees.

Strength of the Lean production system design has attracted attention of other business sectors and many western producers, business branches that have no connections with car production, have started to introduce the principles of Lean production and they have improved their results. These business activities include aluminium companies, airlines and general manufacturing.

Introduction of the Lean production model, which uses its own logic rather than simple copying of techniques, is called "Lean Thinking" and it was popularized by Womack and Jones in the book titled "Lean Thinking". More than fifty examples have been studied in the book and comparison "before and after" the improved enforcement was made. Authors have also set five basic principles of Lean thinking which, when carried out in sequence, generate a high-performance foundation of Lean production.

Lean system is based on the following principles:

- Value and waste

- Identification of value stream - includes all activities necessary to deliver the product to the customer

- Achieving flow through the process - easy movement of products through the process

- Setting the pace to pull signals - a system where the end-customer is helping to create a new product

- Continuous quest for perfection - no errors, defects

1. Term Value can be understood in terms of "WHAT" the customer wants to buy and what provides customer satisfaction. This phase includes understanding the loss in the current production system that stops or postpones the information process and movement of materials to ensure high levels of customer value. General use of "rules" broadly suggests that less than 5 percent of the time spent in material production system is spent on added value (ready for sale, and not to be late, travel, etc.), which increases costs and does not provide real value for customers.

2. It is necessary to determine the flow of values and internal activities undertaken within the company that convert customer target into completed order and activities related to the generation of new products for customers. Once it is understood how production and product design can improve the process, work can be initiated with larger value stream (suppliers and customers) to eliminate waste 
among companies who are in the business of satisfying customers. Value stream mapping is achieved in a way that all activities, all processes and all flows, whether they are material or informational, are mutually linked starting from the raw materials /initial information to the finished product/service, i.e. to the customer. The aim is to identify all forms of waste. It is necessary to analyze current state and develop an improvement plan, define measurable goals, timeframes and responsible people. Philip (Phil) Condit - president and CEO of Boing Company said: "Whenever there is a product for the customer, then there is a value stream. Challenge lies in the fact that it needs to be seen."

3. Creating product flow is the third principle of Lean thinking and it involves keeping materials and movement of information, so that materials "flow" towards the customer without delay or interruption. Long kept stock reduces stock turnaround and that blows up costs and ties up large amounts of capital in the materials that are not sold for profit.

4. Pull production is used when it is not possible to complete the flow of products to customers (due to the number of customers, time constraints, the need for technology and other restrictions). Under this rule, where it is not possible to achieve a uniform flow of production, storage must be designed so that customers' orders could be carried out from a carefully managed place of storing stock by pulling tasks that are necessary in order to carry out orders from this place of storage. In this way it is possible to maintain customer service by future production and finishing. For advanced forms of Lean production it is possible to have a lot of small storage points that are used to connect directly internal customers and suppliers of production operations and to enable orders from customers (removal from the stock of finished products) for a complete pull work through the company. This is known as the kanban system in Toyota and it allows simultaneous current availability of the product and short storage time. The term "pull" implies that nothing is produced until it is requested by internal or external customers. In mass production, each operation is an "isolated stream", it functions by itself and produces according to the schedule (orders) received from the Production Planning Department, regardless of the operation that follows. The planning department plans production according to the forecasts that are often inaccurate. Production is "pushed" towards the customer rather than "pulled" to meet the customer's exact production preferences. Lean solves that in a manner that it produces exactly what the customer wants, with the least possible loss or waste.

5. The last principle and rule of Lean thinking is to seek perfection in every aspect of business and relationship with customers and suppliers. The emphasis here is on 
solving problems of the teams of operators, and managers and teams mutually to remove the last remaining element of loss for non-value added activity.

An integral part of the system is the reduction of variability of the demand, production and suppliers and includes the reduction of variations at the time of the execution of the process - the establishment of standardized procedures. Variability of suppliers is reduced by reducing their number and by introducing partnerships with suppliers. Reducing variability in the processes is introduced by adjusting production, and measure that is used thereby is called "talk time" - the goal is to harmonize production and demand.

All activities in the value chain can be divided into three groups:

- Value-added activities - VAT - a customer is willing to pay. Activity that represents direct operation while performing services. It should be performed without error;

- Non-Value-added activities - NVAT - necessary loss. Activity cannot be eliminated from the process and it does not create value (existing technology, business policy, preparation work, conforming with the regulations...). It does not participate directly in the creation of customer satisfaction, but the producer believes that it should exist.

- Non-Value-added activities - WT - not necessary, net loss!!! Activities that spent resources, but the consumer is not willing to pay (waiting, stock, modifications...). The consumer does not recognize them and they are not willing to pay.

The biggest innovation that Lean management introduces is the fact that opportunities for improvement cannot be found in the activities that create value, but in the activities around them.

Terms "Lean production" and "Lean companies" have become popular for managing technology and they continued to redefine the model after mass organisation. Lean production and Lean system imitation are now being practiced in a wide range of industrial sectors by large and small companies and are rapidly becoming regular company practice.

Loss - waste

Loss and waste are elements of production process, which do not contain any value, i.e. those are activities that do not add direct value to the product. Loss is considered to be anything that creates cost and does not increase value to the customer. Lean management is focused on identifying and eliminating waste. Identifying waste is very challenging, as is the removal itself.

According to Taichi Ohno, there are 7 types of loss (Table 4.): 
- over-production;

- transport;

- waiting time;

- excessive processing;

- stock;

- unnecessary movement;

- scrap

\begin{tabular}{|c|c|c|}
\hline WASTE & IN PRODUCTION & IN OFFICE PROCESSES \\
\hline Over-production & 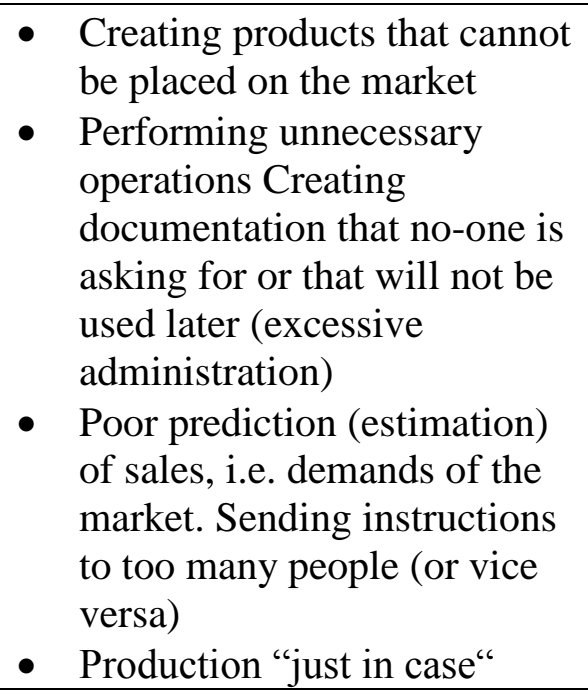 & $\begin{array}{l}\text { Printing documents before } \\
\text { it is necessary (you may } \\
\text { later need to change) } \\
\text { - Ordering goods before it is } \\
\text { necessary (it may be } \\
\text { changed in the meantime) }\end{array}$ \\
\hline Transport & 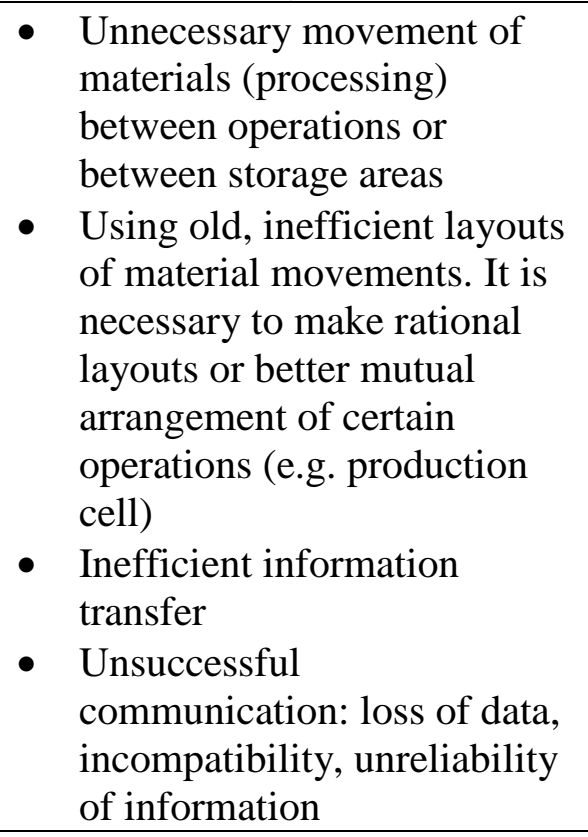 & 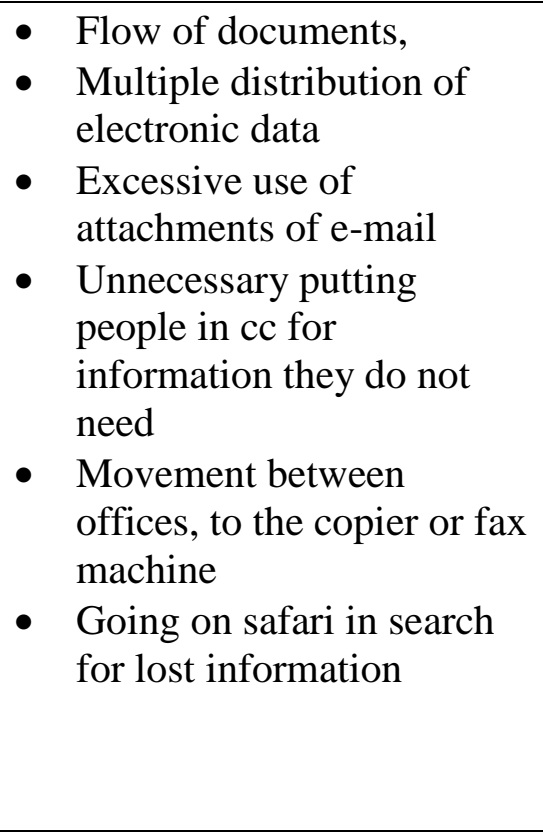 \\
\hline Waiting time & $\begin{array}{l}\text { Waiting time for materials } \\
\text { between operations, waiting } \\
\text { for machine operators (bad } \\
\text { production planning). It is } \\
\text { necessary to thoroughly study } \\
\text { movements in the operations, } \\
\text { synchronize and standardize } \\
\text { production. } \\
\text { - Waiting for the delivery (e.g. }\end{array}$ & $\begin{array}{l}\text { - Low speed of computers } \\
\text { - Waiting for fax, copier, } \\
\text { computer } \\
\text { - Waiting for information } \\
\text { from the customer } \\
\text { - Waiting for clarification or } \\
\text { correction in terms of work } \\
\text { delegated to the } \\
\text { participants in the process }\end{array}$ \\
\hline
\end{tabular}


Stojkic, Z., Visekruna, V. \& Majstorovic, V.: Application of Organizational Tools...

\begin{tabular}{|c|c|c|}
\hline & raw material is late, etc.). & \\
\hline Excessive processing & $\begin{array}{l}\text { Oversized machines, wrong } \\
\text { or missing technological } \\
\text { equipment, preliminary-final } \\
\text { time, cleaning between } \\
\text { processing } \\
\text { - Too much processing } \\
\text { - Poor product design } \\
\text { (construction), which } \\
\text { requires too many processing } \\
\text { steps (product too complex) }\end{array}$ & $\begin{array}{l}\text { - Carrying out inspections } \\
\text { instead of process analysis } \\
\text { and error elimination } \\
\text { - Multiple data input into } \\
\text { different systems } \\
\text { - Making unnecessary } \\
\text { reports }\end{array}$ \\
\hline Stock & $\begin{array}{l}\text { Large stock is associated } \\
\text { with excessive production } \\
\text { (“frozen capital" in } \\
\text { warehouses) }\end{array}$ & $\begin{array}{l}\text { Waiting for goods in } \\
\text { electronic and/or physical } \\
\text { mailboxes to download } \\
\text { - Ordering or making office } \\
\text { materials or books before it } \\
\text { is necessary }\end{array}$ \\
\hline Unnecessary movements & $\begin{array}{l}\text { - Poor arrangement of } \\
\text { machines - unnecessary } \\
\text { movement of workers } \\
\text { - People have to move in order } \\
\text { to obtain information } \\
\text { - Handmade in order to } \\
\text { compensate for any } \\
\text { deficiencies in the production } \\
\text { process }\end{array}$ & $\begin{array}{l}\text { Working conditions in the } \\
\text { office that cause eye } \\
\text { strain, chronic back pain or } \\
\text { other conditions that affect } \\
\text { human health and thus } \\
\text { their productivity }\end{array}$ \\
\hline Scrap & $\begin{array}{l}\text { - Stopping the flow due to } \\
\text { errors, unnecessary time, cost } \\
\text { and space for analysis and } \\
\text { correction } \\
\text { - Incomplete, incorrect, undue } \\
\text { information }\end{array}$ & $\begin{array}{l}\text { Error while creating } \\
\text { account } \\
\text { - Changing orders made by } \\
\text { engineers. }\end{array}$ \\
\hline
\end{tabular}

Tab. 4. Overview of waste in production and administration

A process is a set of activities that have to be performed correctly in proper sequence in order to create value that will be accepted by the client. The main goal of the process approach in a company is that every process has to attain the status of perfect process (process is capable to create precisely the desired value for the customer). Through their needs and demands, customers affect process input.

Outputs of the process go towards the customer that can be external and internal:

- External customer is outside of the company. A typical form of exchange with external customer is the money, i.e. end user is the customer that pays product or service.

- Internal customer is inside the company, and there is no money exchange.

To uphold the basic principles of Lean system (waste removal, flow values, flow through the processes, taking pull signals into account, search for perfection), a number of approaches, techniques and tools is used. 


\section{Lean CRM}

A pioneer in the implementation of Lean CRM is Toyota. In 2003 Toyota expanded Lean principles of management into the CRM field of marketing, sales and services. These are the areas that were the slowest adapting to improve their productivity, despite huge investments in technology over the past decade. It is expected that introducing Lean CRM will revolutionize this areas, even more than in the case of production.

The principles of Lean CRM has been implemented in Toyota. The project was implemented in a number of Toyota sales offices and the goal was reached, not only because of the implemented CRM software and applied Lean tools, but because of step by step implementation.

It is necessary to organise the processes in such a way that they meet customer needs, and they are well organised if they achieve good results on the market. On the other hand, customers are more demanding today than ever before. Today customers expect friendly, competent service, good availability and reliability within the set deadlines, and product quality. It is essential that all company processes are efficient and customer-oriented. At the same time, fast, reliable and simple mechanisms for company management are introduced.

\subsection{Lean xRM and Further Development Directions of xRM tools}

It is possible to automate tools and processes with xRM strategy and by applying new technology that leads to greater efficiency and transparency of processes and simple controlling. Lean management provides methods and techniques for analysing and improving processes, we can see that processes are the focus of xRM and Lean. For this reason, we cannot apply these organisational and software tools in the same way in different environments and expect the same results, but we need to adapt them to a particular company or people in this company.

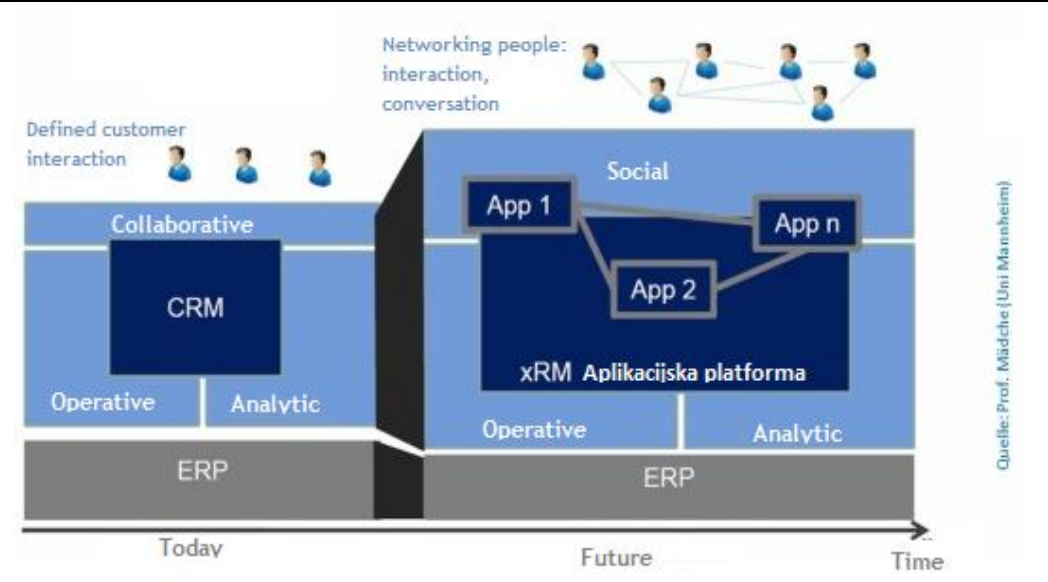

Fig. 2. Development direction of xRM solutions

\section{Concept Implementation of CRM - xRM System in Business}

Implementation of information system in a company is a very important project for a company. Such a project represents not only a significant deployment of 
Stojkic, Z., Visekruna, V. \& Majstorovic, V.: Application of Organizational Tools...

required company resources, but also a significant risk for the economic success of the project itself. For this reason, it is necessary to pay special attention to the planning of these projects.

It is necessary to begin by choosing strategy for the implementation of the project.

Basically there are two possible implementation strategies:

- phasing,

- simultaneous introduction.

In addition to the choice of strategy and standard factors of project success, the following have significant impact on the project outcome:

- Type of the selected software solution in terms of

$\circ$ functionality of the software solution,

$\circ$ reputation of the software designer,

○ software solution reliability,

○ use of reference models,

○ All-round,

○ cutting edge technology

$\circ$ adaptation of solutions to the business practice

- Project contractor of the in terms of

$\circ$ experience in implementing software solutions,

- partnership of the company and the supplier (contractor),

- confidence of users in the capability of the project contractor

- A company that made the introduction of a new system of

o top management support,

- compliance of the IT and projects with the business strategy,

○ broad support for the project,

- transparency of information and procedures in the organisation,

O level of information technology and IT knowledge within the company,

$\circ$ use of modern forms of communication and working in teams,

○ knowledge of project management techniques,

$\circ$ quality training of the users,

$\circ$ duration of the project

The concept of implementation describes and generally regulates the entire process from initiation through implementation to project completion. Since there are a number of different types of information system implementation projects, there are many concepts of implementation described in literature. One concept of the implementation of the new CRM - xRM system in the company will be presented within this chapter.

Implementation of an information system is done in two parts. 
1. implementation of the system in the entire company with achieving basic functionality of the system

2. implementation of the system from the reached level in the first part in implementation to the desired level of the system by applying Lean tools to improve business processes

\subsection{First Phase of the Introduction of CRM - xRM System}

The first part involves implementation of the system in the entire company through two forms of describing the problem. One form defines phases of introducing a new information system in the company, while the other form defines referential organisational model of the company that is adapted to the individual needs of the process of that company.

This part of the introduction of an information system is divided into five stages:

1. Project management

2. Current state analysis

3. Development of a concept that meets company needs

\section{a. Reference models}

4. Installation of the information system

5. Implementation phase

In the project management phase the following things are done: defining goals, creating a project plan, forming a project team and other activities necessary for the realisation and implementation of the project.

In the second phase of the current state analysis the following things are done: process of interviewing, documenting process flows, and defining specific measurement values, which will be further processed through the analysis of the bottlenecks in the process.

In the third phase (Development of a concept that meets company needs), the project team discuss the analysed processes and make a decision on the changes that need to be made. Within the concept development there are developed reference models. On the one hand, these models can be adjusted to the functionality of the software package and its modules. On the other hand, these reference models offer a transparent overview of business processed that can be adapted to the individual needs of the company and simultaneously serve as a basis for customizing the software to company needs.

The forth phase is editing, i.e. setting the information system parameters. The fifth and final phase, perhaps the most important stage, is implementation of the software as well as systematic and organisational documentation. In the implementation phase it is necessary to pay attention to the order of realisation of certain steps in order to quickly see the benefits of the introduction of the new CRM $\mathrm{xRM}$ system. Return on investment at this stage has very high priority. 
Stojkic, Z., Visekruna, V. \& Majstorovic, V.: Application of Organizational Tools...

\subsection{Second Phase of the Implementation of CRM - xRM System}

After the implementation of the CRM - xRM system, Lean tools are used in the next step of implementation to improve business processes (KAIZEN, Value stream mapping).

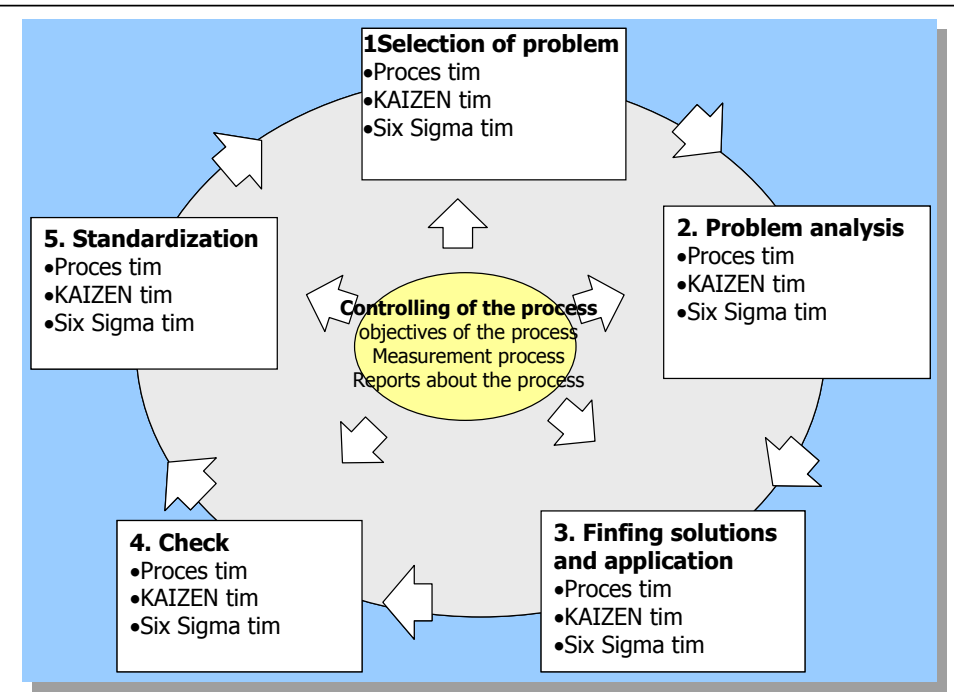

Fig. 3. Second phase of the implementation of the information system (Slama, 2011)

In this part of information system implementation, major engagement of company employees is present with minimal involvement of consultants or programmers. More effects occur through the second step of information system implementation and simultaneous application of methods to improve business processes. Information and data requirements for establishing a control system for the processes are set in the first step of information system implementation, and that represents a prerequisite for the implementation of methods to improve business processes. In the implementation of the methods for the improvement of business processes all employees will be engaged to improve business processes, and those improvements will be integrated into the information system, which will ensure additional quality and speed within business processes.

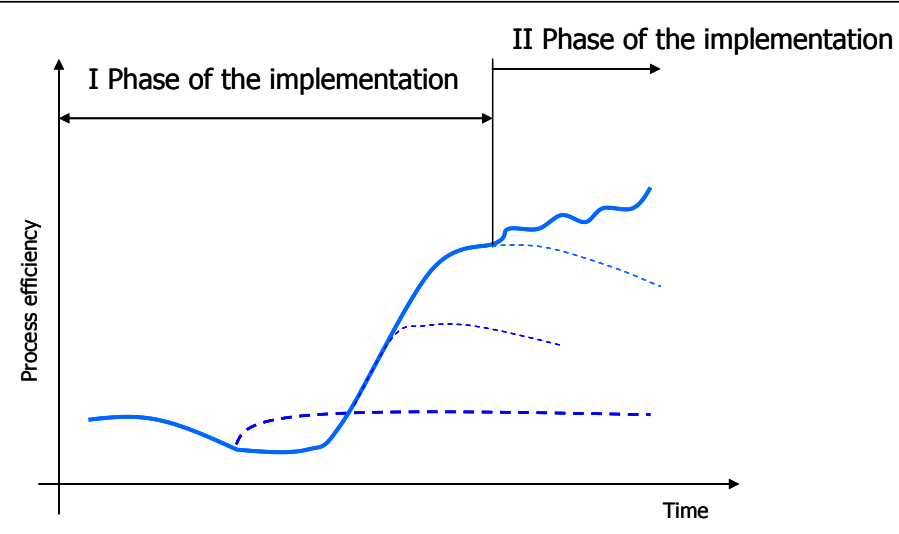

Fig. 4. Stages of the implementation of the information system (Slama, 2011) 
Figure 4 shows stages of the information system implementation in relation to the efficiency of business processes. The process of the implementation of CRM $\mathrm{xRM}$ solutions has an impact on the efficiency of business processes in the company. One part of the companies cancel further implementation of the system in the first phase of the implementation and thus the efficiency of business processes remains unchanged. Increase in the efficiency of the business processes that are covered by a new system is visible over time in the companies that continue with implementation. Also, failure to execute the second phase of the implementation of the CRM - xRM system leads to a drop of efficiency of business processes. For this reason, it is necessary to apply Lean tools at this stage as instruments that will help in the further analysis and improvement of business processes.

\section{Conclusion}

In this chapter we wanted to point out the necessity of linking organisational tools such as Lean tools and CRM - xRM software solutions. Both groups of these tools are focused of processes which have to be more efficient. Through the described concept of the software solution implementation and application of Lean tools, efficiency of business processes can be significantly improved. The concept proposed allows that the company which is introducing the new CRM - xRM system has insight into the costs, duration and progress of the project from the beginning of the project. In addition, the company can use the moment of CRM - xRM system implementation to change and improve business processes with continuous improvement of the processes in the future. With this concept, activities of introducing a new CRM - xRM system become transparent and clear, and thus it is possible to control and achieve the set project goal. This implementation concept allows for parallel enhancement and improvement of company business processes by applying Lean tools as well as automation of business processes through CRM xRM system implementation.

This concept allows transparent measurement of the improvement of business processes caused by the implementation of the new information system. The disadvantage of this methodology is reflected in the time required for implementation. Implementation time is significantly longer compared to the standard methodologies, however, this method achieves higher frequency in the use of the selected software tool and, of course, greater efficiency of business processes.

Lean as an organizational tool has many applications in manufacturing, but recently there has been an increase of in its application in the area of administrative processes. This organizational tool in itself represents a potential to achieve innovation and reduce costs within the business process. On the other hand, xRM tools are already enabling us to automate one part of the administrative operations within business processes.

Thanks to the technological developments end users are now able to shape certain segments of business operations through the xRM software solutions without the need for significant programming input in the process. In the future, the number and range of possible xRM tool applications will continue to grow, as will the 
number of the business processes they are used for and the flexibility of the very tool itself. XRM as a software tool is not and will not be a replacement for the ERP system, but rather its extension to the administrative processes the ERP does not cover. By combining organisational (Lean) and software (xRM) tools we are now able to achieve a manifold effect on the increase of administration efficiency and transparency as the application of Lean tools improves and develops business operations, while the XRM tools automate them at the same time. One of the main future challenges to combine the application of Lean and XRM tools in improving administrative processes. Simultaneous application of these tools requires multidisciplinary knowledge (organisational and IT) from both individuals and teams, and as such it represents a challenge in terms of selecting their adequate application in practice.

\section{References}

Allweyer, Th., (2005) Geschäftsprocessmanagement. Strategie, Entwurf, Implementirung, Controling. Herbecke

Broechler, K, Schönberger, C., (2004) Six sigma für den Mittelstand, Campus Verlag Frankfurt/ New York.

Bulinger, H-J. (2003). Neue Organisations-formen im Unternehmen, Springer, 2. Auflage, ISBN 3540-60263-1, Stuttgart

Davenport, T.H. (1993) Proces Inovation: Reenginering Work through Information Technology, Harvard Bysiness School Press

EL Sawy, (1993) Redesigning enterprise processes for e-Business, McGrow- Hill

Gadatsch, A., (2005) Grundkurs Geschäftsprocessmanagement. Metoden und Werkzeugen für die IT-Praxis, Wiesbaden

Hammer M., Champy J. (1993) Reenginering the Corporation: A Manifest for Business Revolution, Harper Business

http://arhiva.trend.hr/clanak.aspx?BrojID=71\&KatID=22\&ClanakID=783

http://www.articlesbase.com/software-articles/modules-of-crm-solutions-1158092.html

http://www.intellitecsolutions.com/documents/MakingSenseofXRM.pdf

http://www.productivityinc.com/pdf/MoMRwebcast5.pdf, Mapping your way to Lean Maintenance, John Kravontka

J.Schmelzer H., Sesselmann, W., (2008) Geschäftsprozess-management in der Praxis, Hanser Verlag, ISBN 978-3-446-41002-2 München

James P. Womack \& Daniel T.Jones: Lean thinking, Simon \& Schuster, Inc. 2003

James P.Womack, Daniel T.Jones \& Daniel Roos: The Machine that change a world, The Story of Lean production, Harper Collins Publishers, Seamon\&Schuster UK Ltd, 2007

Martens, P., (2009) Integrierte Informationsverarbeitung 1, Gabler Verlag, ISBN 978-3-8349-16457, Wiesbaden

Mitchell I. Kramer, Comparing CRM Architectures -, 2002., Patricia Seybold Group

Müller, J., Srića, V., Upravljanje odnosnom s klijentima, Delfin, Zagreb, 2005

Slama D, NeliusEnterprise R. (2011) BPM: Erfolgsrezepte für unternehmensweites Prozessmanagement, dpunkt.verlag. ISBN 978389864 6871, Heidelberg

Stojkic Z, Majstorovic I. (2012) Paper: Improving business organisation through the implementation of integrated IS, Annals of DAAAM for 2012 \& Proceedings of the 23rd International DAAAM Symposium, ISBN 978-3-901509-91-9 , DAAAM International, Vienna, Austria 